\title{
A Case of Early FAP Diagnosis with Extraintestinal Manifestations on the Face
}

\author{
Vasilios Thomaidis, Konstantinos Seretis, Gregory Tsoucalas, Konstantinos Razos, \\ Anastasios Vasilopoulos, Gioultzan Memet Efenti, Aliki Fiska
}

\author{
Anatomy Department, School of \\ Medicine, Democritus University \\ of Thrace, Alexandroupolis, Greece \\ Correspondence: \\ gregorytsoucalas@yahoo.gr \\ Tel.: + 306945298205 \\ Fax.: + 302421078160
}

Received: 10 December 2018 Accepted: 26 March 2019

Key Words: Gardner's Syndrome • Osteoma - Polyposis of the Colon.

\begin{abstract}
Objective. Gardner's syndrome is a variant of familial adenomatous polyposis, characterized by gastrointestinal polyps, multiple osteomas, and skin and soft tissue lesions. Diagnosis by means of an understanding of its various symptoms is of great importance. Case report. This report presents the case of a 32-year-old man with obvious asymmetry and disfigurement on his face, due to multiple osteomas and soft tissue lesions. These clinical signs prompted us to further investigation, leading to the diagnosis of a case of Gardner's syndrome, with asymptomatic polyposis of the colon. Polyps have virtually an almost $100 \%$ risk of undergoing malignant transformation. Conclusion. Early diagnosis and treatment of this pathological entity are crucial, while the presence of osteomas should alert us to this diagnosis.
\end{abstract}

\section{Introduction}

Gardner's syndrome (GS), a phenotypic variant of familial adenomatous polyposis (FAP), is a rare autosomal dominant disease, characterized by a classical triad of signs: a) gastrointestinal polyps, b) multiple osteomas and c) skin and soft tissue lesions. Polyps have a very high risk, of almost $100 \%$, of undergoing malignant transformation, in untreated cases $(1,2)$. Although Menzel was the first to describe the adenomatosis of the colon in 1721 (3), it was Gardner in 1951 who noted the significant correlation between extra-intestinal osseous and cystic tumours and FAP, a relationship which presented a very high probability for future malignancy (4). In the following years, alongside his colleagues, he proved that the syndrome had a dominant hereditary pattern of inheritance $(5,6)$. Multiple osteomas and soft tissue lesions with obvious asymmetry on the face, as the first manifestation of the disease, have been reported rather rarely as an early diagnostic sign of GS. We therefore present this case to alert clinicians to the possible existence of gastrointestinal pathology associated with signs in the maxillofacial region.

\section{Case Report}

A 32-year-old Caucasian man of Hellenic origin presented with an asymptomatic mass causing disfigurement in the left preauricular area. The mass had appeared 8 years previously and was gradually growing in size. During the physical examination a hard, fixed mass was palpable, while similar masses, smaller in size, were revealed at the angle of the mandible, bilaterally. The lat- 


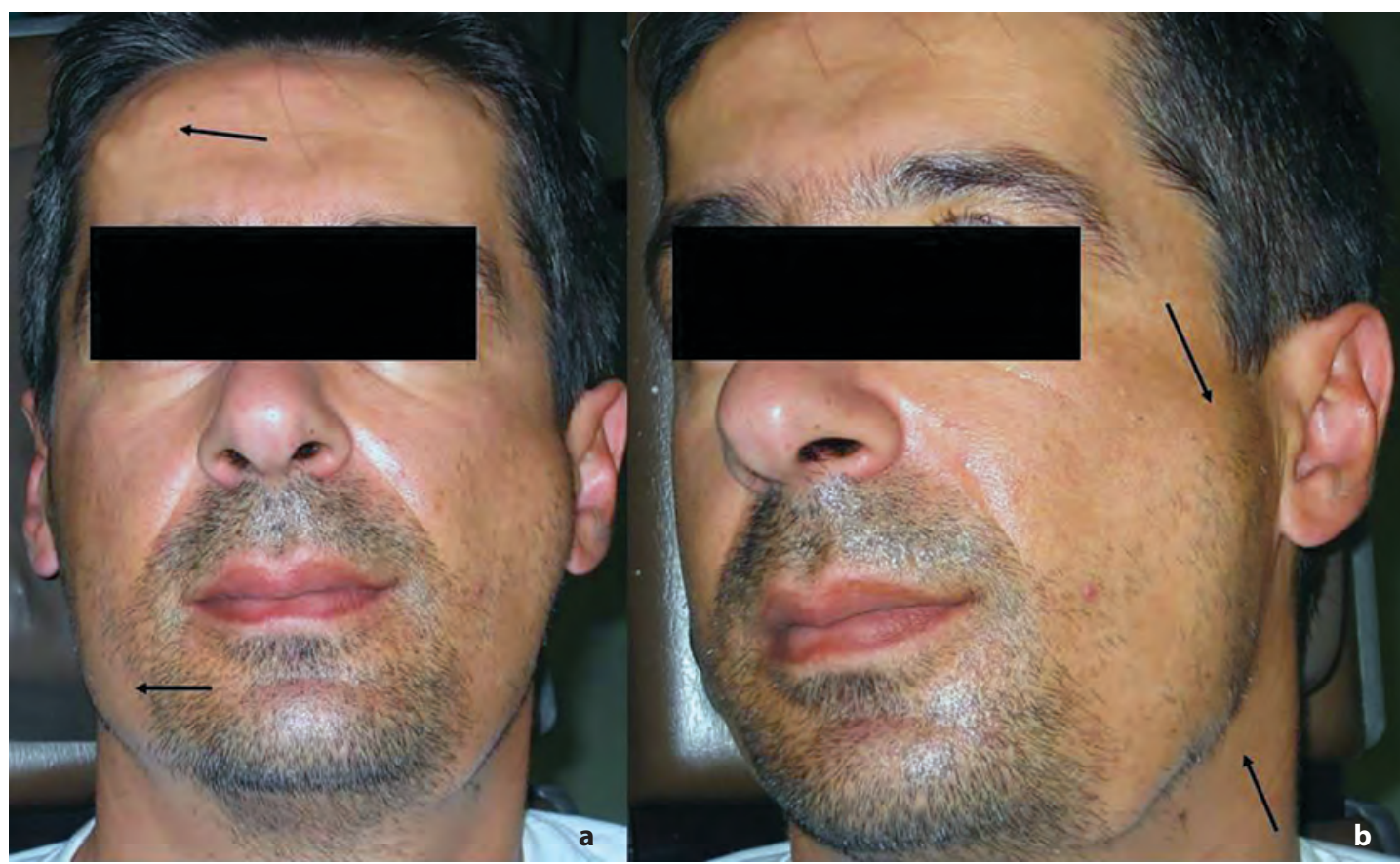

Figure 1. A: Photograph of the patient showing disfigurement of the left preauricular region and the right forehead. B: Photograph of the patient showing a swelling at the left angle of the mandible.

ter had been present since adolescence, and had been forgotten and somehow neglected by the patient. There were also three small sclero-elastic swellings in the soft tissues of the right forehead, with an appearance similar to lipomas or epidermoid cysts (Figure 1
$\mathrm{A}$ and $\mathrm{B})$. The patient mentioned no other symptoms of acute or chronic character.

Orthopantomography revealed multiple well-defined opacities of the mandible and maxilla (Figure 2). During a computed tomography (CT) examination, an osteoma,

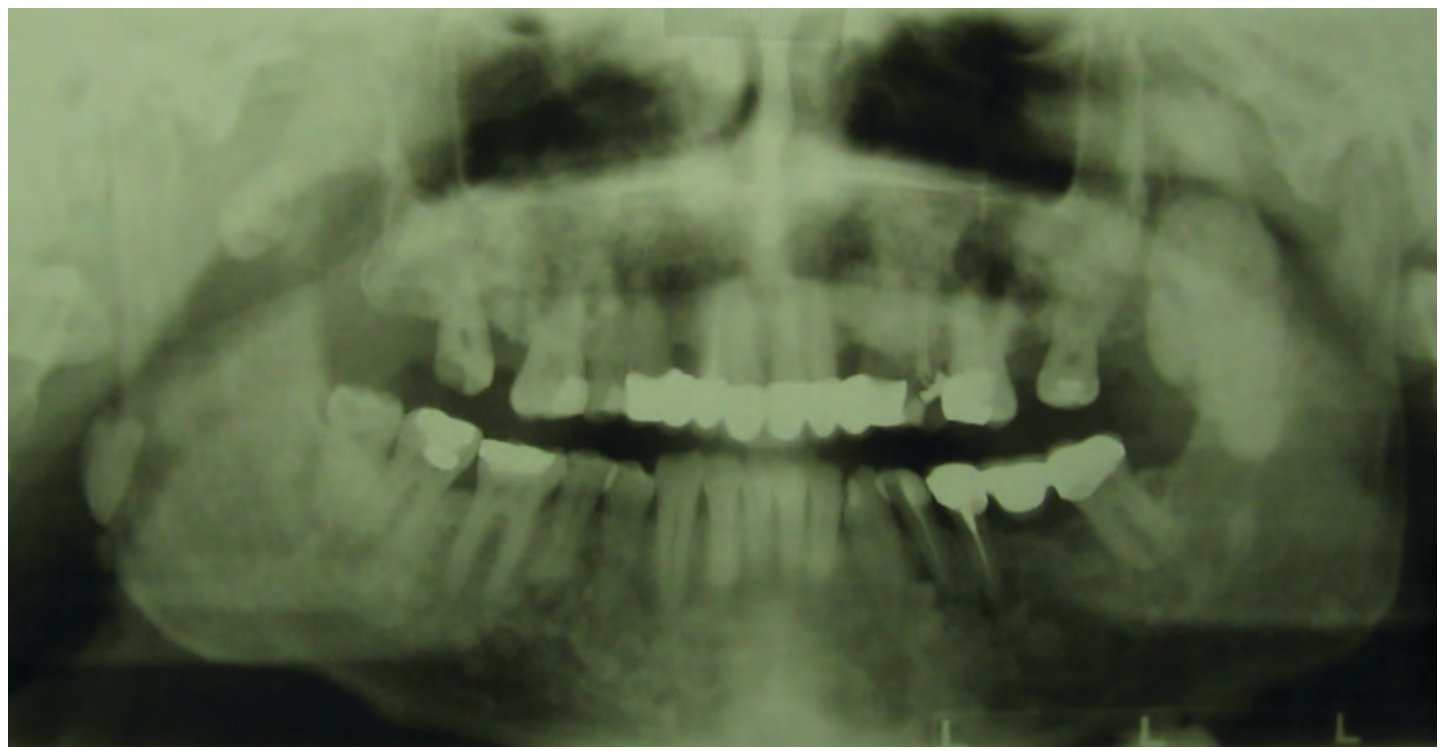

Figure 2. Panoramic radiograph showing multiple radiopaque lesions of the mandible and maxilla. 


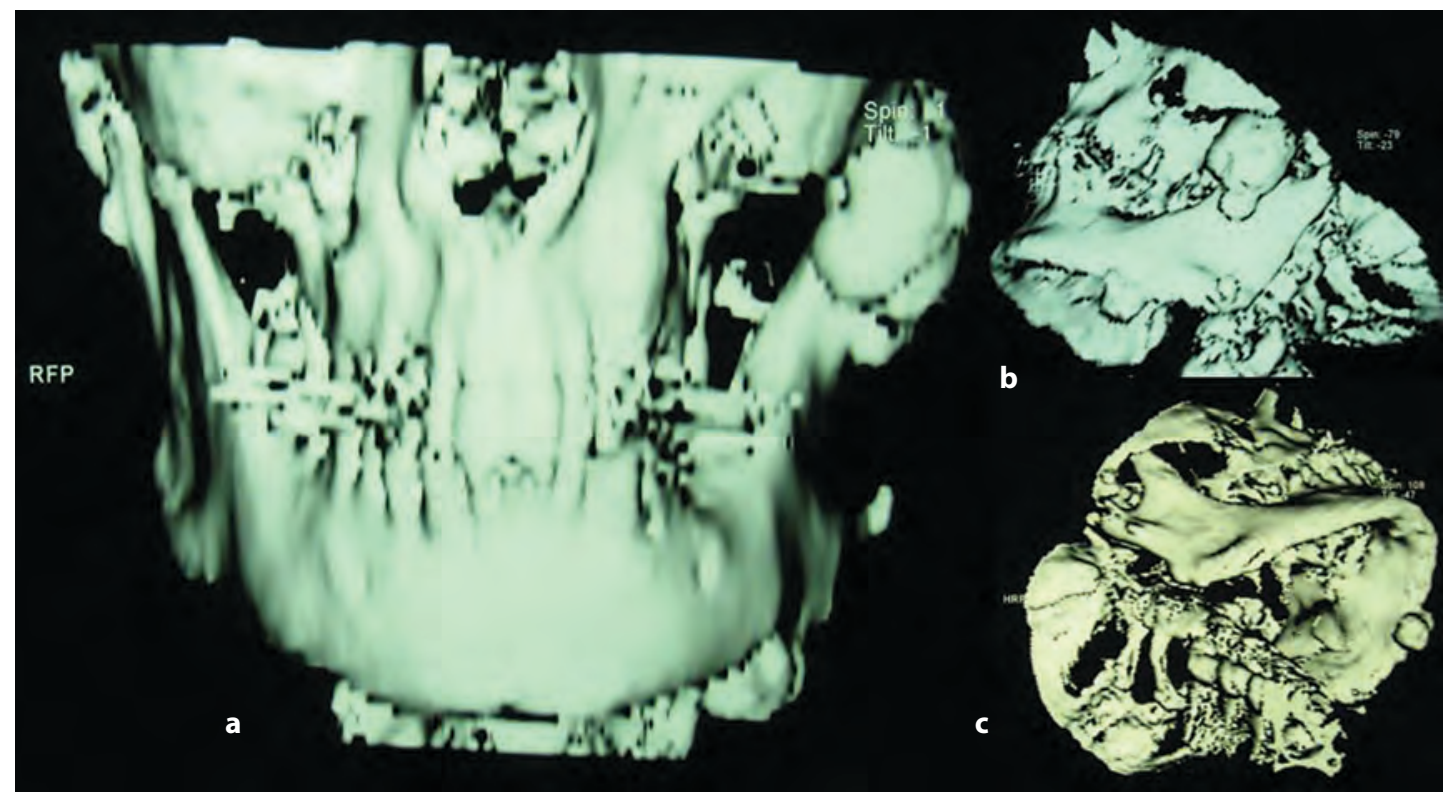

Figure 3. A, B and C: Computed tomography scans showing multiple osteomas of the mandible, maxilla, left ramus, maxillary antrum and pterygoid processes.

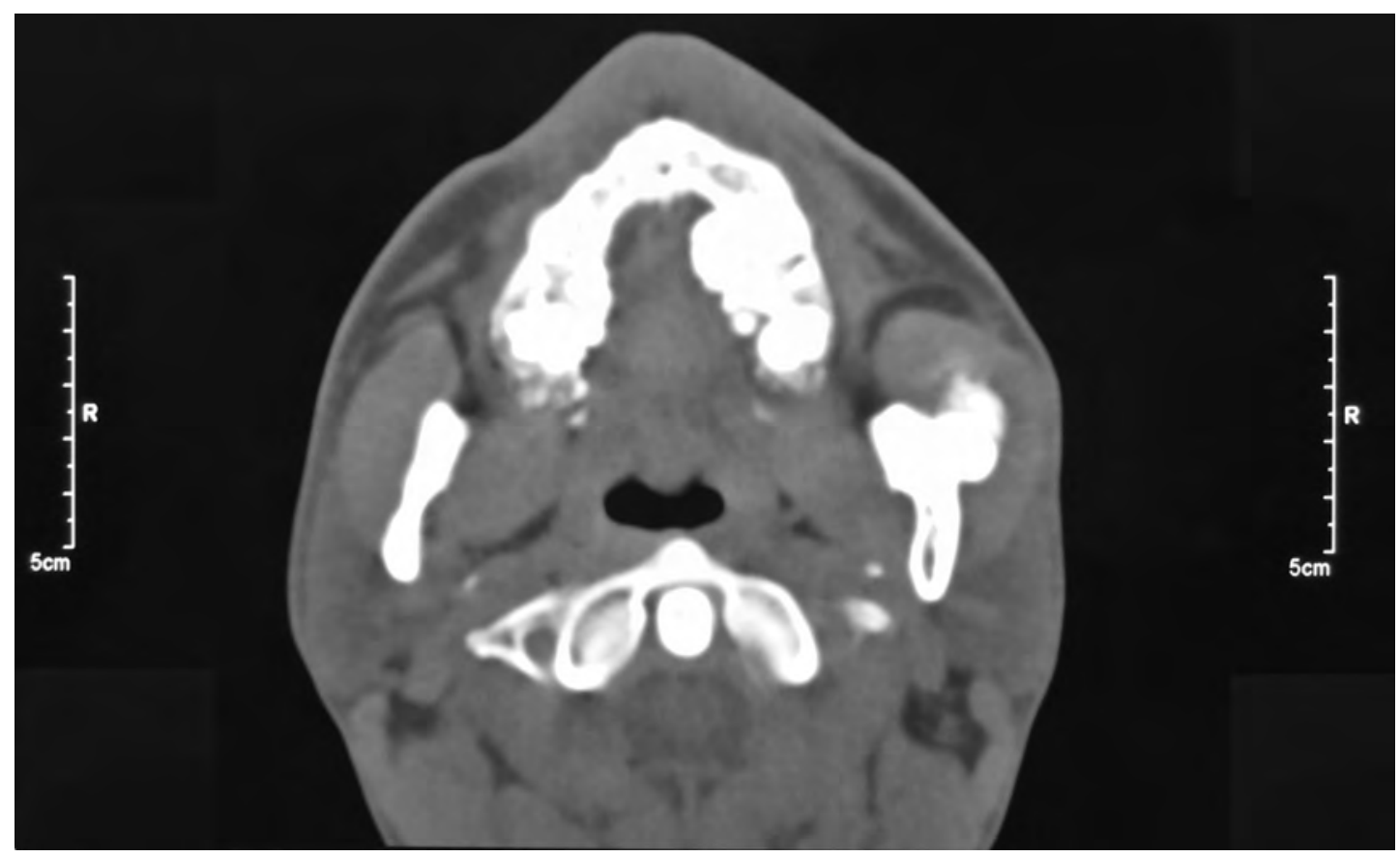

Figure 4. Three-dimensional CT-scan demonstrating the multiple osteomas.

with a maximum diameter of $3 \mathrm{~cm}$, was detected on the superior part of the left ramus. Similarly, multiple smaller osteomas of the mandibular angles, right ramus, the temporomandibular joint, maxilla, maxillary antrum and pterygoid processes were also detected (Figure 3 A, B and C; Figure 4).

The suspicion of possible GS guided our team towards a more detailed clinical examination and further diagnostic investiga- 


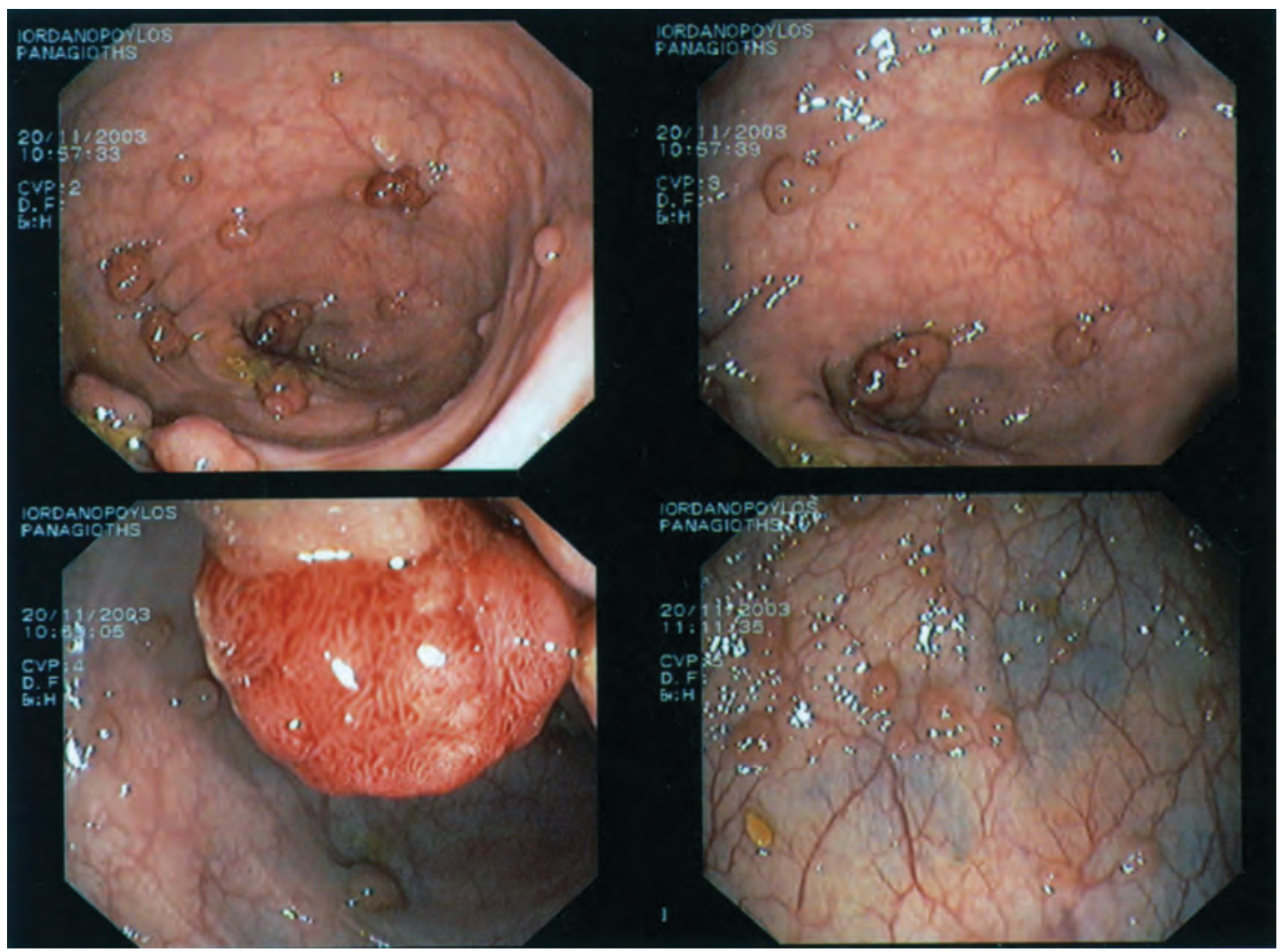

Figure 5. Multiple polyps of the intestine revealed by colonoscopy.

tion. The patient mentioned no complaints regarding his bowel function, while a routine physical examination showed no other positive relevant findings. According to his family history, there were no recorded cases or suspicion of familial polyposis syndrome. Routine laboratory examination showed all results within the normal limits. Although it might have been a case of lipomas, or multiple osteomas, a possible diagnosis of a GS was considered. Thus, the patient was referred for an urgent colorectal examination. Barium passage of the intestine and colonoscopy up to $120 \mathrm{~cm}$ were requested. Myriads of small, sessile polyps carpeting the colon were eventually detected (Figure 5). Histological analysis of the biopsied polyps showed adenomas of the colon. Moreover, a CT scan of the abdomen showed no evidence of soft tissue tumours intraperitoneally or retroperitoneally, while the ophthalmologi- cal examination was negative for congenital hypertrophy of the retinal pigmented epithelium (CHRPE). An ultrasound examination of the patient's neck showed the normal size and echogenicity of the thyroid gland. Long bone $\mathrm{x}$-rays revealed no signs of other bone lesions.

The extraintestinal manifestations of the face combined with the plethora of polyps resulted in the final diagnosis of GS. A proctocolectomy with ileal pouch-anal anastomosis was performed a few days later. The postoperative course was uneventful and histological examination of the specimen confirmed a case of a plethora of adenomatous polyps, none of which had transformed malignantly. A thorough screening examination of all first-degree relatives of the patient was negative for FAP. During the follow-up the patient presented no signs of malignancy over a two year period, while 
after that he neglected his preventive examinations.

\section{Discussion}

GS is inherited, with an autosomal dominant pattern with complete penetrance and variable expressivity, while one third of cases are spontaneous mutations, with no family history reported $(1,2)$. It is linked genetically to chromosome band 5q21, and the adenomatous polyposis coli (APC) locus. More than 200 mutations have been reported in the literature (7-10). The exact position at which the APC gene is mutated determines the manifestations and severity of the GS (11).

GS occurs in 1 person per million, while the incidence of FAP occurs in between 1 case out of 8,300 people and 1 out of 14,025 $(12,13)$. GS is characterized by extensive adenomatous polyps in the colon, which may also develop in any anatomical position of the gastro-intestinal tract (14). Although they begin to form in puberty, the average age of diagnosis is 22 years. Nevertheless, a number of paediatric cases have also been reported with a mean age of GS appearance of $4.1 \pm 3.6$ years for males and $5.0 \pm 3.7$ years for females (15). The patient may present with intermittent mucus discharge with defecation, bleeding per rectum, diarrhoea and abdominal pain. On the other hand, many patients seek medical care for cosmetic reasons (16), being unaware of the significance of the GS. Polyps tend to progress to malignancy in nearly $100 \%$ of untreated cases. However, in studies rates vary from $58 \%$ to $100 \%(17-20)$, while there are some reports of patients who received no treatment and remained free of malignancy (21). Malignancy is usually diagnosed in patients between 30 to 50 years of age, with an average age of diagnosis of 39.2 years $(2,22)$.

Extracolon manifestations, such as osteomas and soft tissue tumours, in many cases may precede the polyposis and there- fore may contribute to an early diagnosis of a case of GS. Studies showed that $62-80 \%$ of patients with GS have osteomatous lesions, which are commonly detected during their second decade of life, as opposed to osteomas non-related to GS, which are revealed during the sixth decade $(23,24)$. Osteomas can be detected either during routine examinations or when they reach a considerable size, causing disfigurement. The mandible, especially its angle, is the most common location. However, osteomas may grow in the maxilla, the skull and the long bones (2528). The case reported here presented with obvious asymmetry on the face, particularly in the left preauricular area and mandibular angle, due to multiple osteomas. Although a solitary osteoma of the jaw is a common incidental radiographic finding, if more than three are discovered, there is a high possibility of GS $(29,30)$. These manifestations, along with the soft tissue lesions on the patient's forehead, alerted us, resulting in an early diagnosis of GS with asymptomatic, benign polyposis of the colon, and therefore a postoperative course with an excellent prognosis.

Soft tissue lesions in GS include epidermoid cysts, in $50 \%-65 \%$ of patients, as well as lipomas, leiomyomas, neurofibromas and pigmented skin lesions (17). In our case, we also diagnosed three epidermoid cysts on the forehead. Cysts may also be detected in the scalp and extremities. However, the clinical examination of our case was negative. Osteomas and epidermoid cysts constitute early manifestations of GS, as they usually develop during puberty and may precede the formation of FAP. The late onset of symptoms, with the first suspicion of a facial deformity at the age of 24 , and their diagnostic identification at the age of 32 , with no manifestation of a FAP and its symptoms, is a rare case, in terms of a diagnostic approach to GS. The chronic asymptomatic presence of multiple colon polyps may limit the clini- 
cal signs in the anterior skull area, rendering the task of correct diagnosis particularly difficult. Other clinical signs, such as CHRPE, which is frequently present in up to $80 \%$ of cases and may appear shortly after birth, or various dental abnormalities (e.g. unerupted, impacted, or supernumerary teeth) were not detected (31-34). Moreover, our clinical examination for fibromatous lesions was negative, while no other neoplasms, which may also appear simultaneously (e.g. thyroid carcinoma, periampullary carcinoma, osteosarcoma, liposarcoma, hepatoblastoma, adrenal adenoma and carcinoma) were identified (35-41). All those facts further diminished an obvious diagnosis of GS.

As colon polyps are an extremely highrisk lesion for malignant transformation, a surgical proctocolectomy with ileal pouchanal anastomosis was quickly performed. An alternative surgical approach suggested was colectomy with ileo-rectal anastomosis, which presents a $25 \%$ to $59 \%$ chance of rectal carcinoma and requires annual endoscopic surveillance of the rectum, so it was therefore excluded (2). The postoperative follow-up necessitates a multidisciplinary approach. Duodenal cancer occurs in about $5 \%$ of FAP patients following colectomy, and therefore upper gastrointestinal endoscopy is also required, intermittently, until the patient reaches the age of 50 years (41). The increased prevalence of thyroid carcinoma (100-fold of the general population), also necessitates periodical diagnostic screening $(36,42)$. Finally, a periodic radiographic examination of the jaws should be performed regularly, as osteomas continue to develop in adulthood.

Genetic tests may reveal a mutation in the APC gene in about $85 \%$ of individuals with FAP. This involves the simple and accurate screening of the family $(43,44)$. It is particularly useful for children who, if they have not inherited the damaged gene, will never have to undergo a bowel screen- ing procedure. In families where a mutation cannot be detected, the only possible way to identify affected individuals is by bowel screening. All first-degree family members have to be screened from the age of 12 . However, if no polyps develop by the age of 40 , the screening may be discontinued (45).

Knowledge about maxillofacial findings which are a hallmark for diagnosis of GS is of fundamental importance $(18,46)$. Our case of GS was an isolated familial incident, maybe the first in this family. Several studies suggest that osteomas are important manifestations of GS, and regardless of the absence of a family history of FAP, their occurrence should prompt a diagnostic evaluation related to this disease (47).

\section{Conclusion}

GS is characterized by gastrointestinal polyps, multiple osteomas and cutaneous and soft tissue tumours. Although it is rarely diagnosed, clinical physicians and dentists should be aware of the common and early manifestations which may appear before any FAP symptomatology, as there is an almost $100 \%$ risk that the polyps will undergo malignant transformation at an early age. Therefore, early stage detection and treatment of GS is crucial.

\section{What Is Already Known on this Topic}

GS is a rare syndrome consisting of hereditary intestinal polyposis, accompanied by osteomas, and multiple cutaneous and subcutaneous lesions. In some cases, osteomas emerge before the diagnosis of GS could be established.

\section{What this Study Adds}

Maxillofacial demonstrations of GS may be the first to be noticed. Our case demonstrates how a patient, referred for mainly cosmetic reasons, could suffer from GS, a syndrome which should be diagnosed early by practitioners due to the very high risk of malignant transformation of the FAP.

Authors' Contributions: Conception and design: VT; Acquisition, analysis and interpretation of data: VT, AV, GME and KS; Drafting the article: GT and KR; Revising it critically for important intellectual content: 
VT; Approved final version of the manuscript: VT and AF.

Conflict of Interest: The authors declare that they have no conflict of interest.

\section{References}

1. Bussey HJ, Veale AM, Morson BC. Genetics of gastrointestinal polyposis. Gastroenterology. 1978;74(6):1325-30.

2. Luk GD. Diagnosis and therapy of hereditary polyposis syndromes. Gastroenterologist. 1995;3(2):153-67.

3. Menzel D. The description and observation of the adenomatosis of the colon [in Latin]. Acta Medicorum Berlinensium. 1721;1(9):78.

4. Gardner EJ. A genetic and clinical study of intestinal polyposis, a predisposing factor for carcinoma of the colon and rectum. Am J Hum Genet. 1951;3(2):167-76.

5. Gardner EJ, Plenk HP. Hereditary pattern for multiple osteomas in a family group. Am J Hum Genet. 1952;4(1):31-6.

6. Gardner EJ, Richards RC. Multiple cutaneous and subcutaneous lesions occurring simultaneously with hereditary polyposis and osteomatosis. Am J Hum Genet. 1953;5(2):139-47.

7. Groden J, Thliveris A, Samowitz W, Carlson M, Gelbert L, Albertsen H, et al. Identification and characterization of the familial adenomatous polyposis coli gene. Cell. 1991;66(3):589-600.

8. Joslyn G, Carlson M, Thliveris A, Albertsen H, Gelbert L, Samowitz W, et al. Identification of deletion mutations and three new genes at the familial polyposis locus. Cell. 1991;66(3):601-13.

9. Kinzler KW, Nilbert MC, Vogelstein B, Bryan TM, Levy DB, Smith KJ, et al. Identification of a gene located at chromosome $5 \mathrm{q} 21$ that is mutated in colorectal cancers. Science. 1991;251(4999):136670.

10. Nishisho I, Nakamura Y, Miyoshi Y, Miki Y, Ando $\mathrm{H}$, Horii A, et al. Mutations of chromosome 5q21 genes in FAP and colorectal cancer patients. Science. 1991;253(5020):665-9.

11. Davies DR, Armstrong JG, Thakker N, Horner K, Guy SP, Clancy T, et al. Severe Gardner syndrome in families with mutations restricted to a specific region of the APC gene. Am J Hum Genet. 1995;57(5):1151-8.

12. Alm T, Licznerski G. The intestinal polyposis. Clin Gastroenterol. 1973;2:577-602.

13. Panjwani S, Bagewadi A, Keluskar V, Arora S. Gardner's Syndrome. J Clin Imaging Sci. 2011;1:65.
14. Jagelman DG, DeCosse JJ, Bussey HJ. Upper gastrointestinal cancer in familial adenomatous polyposis. Lancet. 1988;1(8595):1149-51.

15. Goral D, Highland J, Lovell MA, Chan KH. Head and neck presentation of Gardner Syndrome: A pediatric case series. Int J Pediatr Otorhinolaryngol. 2018;110:31-3.

16. Agrawal D, Newaskar V, Shrivastava S, Nayak PA. External manifestations of Gardner's syndrome as the presenting clinical entity. BMJ Case Rep. 2014;2014.

17. Ascari-Raccagni A, Baldari U, Righini MG. Cutaneous symptoms of Gardner's syndrome. J Eur Acad Dermatol Venereol. 1999;12(1):80-1.

18. Bilkay U, Erdem O, Ozek C, Helvaci E, Kilic K, Ertan Y, et al. Benign osteoma with Gardner syndrome: review of the literature and report of a case. J Craniofac Surg. 2004;15(3):506-9.

19. Harrison's principles of internal medicine. 14th ed. New York: McGraw-Hill Book Company; 1998. p. 572.

20. Vaynsthein G, Gurlanik L, Markel A. Gardner's syndrome in a 75-year-old woman. Intern Med. 2008;47(16):1491-4.

21. Perniciaro C. Gardner's syndrome. Dermatol Clin. 1995;13(1):51-6.

22. Aletaha M, Fateh-Moghadam H. Gardner Syndrome. J Ophthalmic Vis. 2012;7(3):257-60.

23. Schneider LC, Dolinsky HB, Grodjesk JE. Solitary peripheral osteoma of the jaws: report of case and review of literature. J Oral Surg. 1980;38(6):452-5.

24. Adisen MZ, Okkesim A, Misirlioglu M. The importance of early diagnosis of gardner's syndrome in dental examination. Niger J Clin Pract. 2018;21(1):114-6.

25. Seehra J, Patel S, Bryant C. Gardner's Syndrome revisited: a clinical case and overview of the literature. J Orthod. 2016;43(1):59-64.

26. Ida M, Nakamura T, Utsunomiya J. Osteomatous changes and tooth abnormalities found in the jaw of patients with adenomatosis coli. Oral Surg Oral Med Oral Pathol. 1981;52(1):2-11.

27. Sayan NB, Uçok C, Karasu HA, Günhan O. Peripheral osteoma of the oral and maxillofacial region: a study of 35 new cases. J Oral Maxillofac Surg. 2002;60(11):1299-301.

28. Harned RK, Buck JL, Olmsted WW, Moser RP, Ros PR. Extracolonic manifestations of the familial adenomatous polyposis syndromes. Am J Roentgenol. 1991;156(3):481-5.

29. Katou F, Motegi K, Baba S. Mandibular lesions in patients with adenomatosis coli. J Craniomaxillofac Surg. 1989;17(8):354-8. 
30. Blair NP, Trempe CL. Hypertrophy of the retinal pigment epithelium associated with Gardner's syndrome. Am J Ophthalmol. 1980;90(5):661-7.

31. Bull MJ, Ellis FD Sato S, Weaver DD. Hypertrophy of retinal pigment epithelium in Gardner's syndrome. Proc Greenwood Genet Center. 1985;4:136.

32. Fader M, Kline SN, Spatz SS, Zubrow HJ. Gardner's syndrome (intestinal polyposis, osteomas, sebaceous cysts) and a new dental discovery. Oral Surg Oral Med Oral Pathol. 1962;15:153-72.

33. Halling F, Merten HA, Lepsien G, Honig JF. Clinical and radiological findings in Gardner's syndrome: a case report and follow-up study. Dentomaxillofac Radiol. 1992;21(2):93-8.

34. Chelaïfa K, Bouzaïdi K, Chouaïb S, Azaïz O, Messaoud MB, Slim R. Adrenal adenoma in a patient with Gardner's syndrome. A case report. Acta Radiol. 2003;44(2):158-9.

35. Harned RK, Williams SM. Familial polyposis coli and periampullary malignancy. Dis Colon Rectum. 1982;25(3):227-9.

36. Herve R, Farret O, Mayaudon H, Helie C, Denee JM, Bauduceau B, et al. Association of Gardner Syndrome and thyroid cancer [in French]. Presse Med. 1995;24:415.

37. Hughes LJ, Michels VV. Risk of hepatoblastoma in familial adenomatous polyposis. Am J Med Genet. 1992;43(6):1023-5.

38. Krush AJ, Traboulsi EI, Offerhaus JA, Maumenee IH, Yardley JH, Levin LS. Hepatoblastoma, pigmented ocular fundus lesions and jaw lesions in Gardner syndrome. Am J Med Genet. 1988;29(2):323-32.
39. Offerhaus GJ, Giardiello FM, Krush AJ, Booker SV, Tersmette AC, Kelley NC, et al. The risk of upper gastrointestinal cancer in familial adenomatous polyposis. Gastroenterology. 1992;102(6):1980-2.

40. Wehrli BM, Weiss SW, Yandow S, Coffin CM. Gardner-associated fibromas (GAF) in young patients: a distinct fibrous lesion that identifies unsuspected Gardner syndrome and risk for fibromatosis. Am J Surg Pathol. 2001;25(5):645-51.

41. Spigelman AD, Arese P, Phillips RK. Polyposis: the Peutz-Jeghers syndrome. Br J Surg. 1995;82:13114.

42. Bell B, Mazzaferri EL. Familial adenomatous polyposis (Gardner's syndrome) and thyroid carcinoma. A case report and review of the literature. Dig Dis Sci. 1993;38(1):185-90.

43. Armstrong JG, Davies DR, Guy SP, Frayling IM, Evans DG. APC mutations in familial adenomatous polyposis families in the Northwest of England. Hum Mutat. 1997;10(5):376-80.

44. Giardiello FM, Petersen GM, Piantadosi S, Gruber SB, Traboulsi EI, Offerhaus GJ, et al. APC gene mutations and extraintestinal phenotype of familial adenomatous polyposis. Gut. 1997;40(4):521-5.

45. Buch B, Noffke C, de Kock S. Gardner's syndrome-the importance of early diagnosis: a case report and a review. SADJ. 2001;56(5):242-5.

46. Silva CA, Moraes Pde C, Furuse C, Junqueira JL, Thomaz LA, de Araújo VC. Gardner syndrome with no clinical family history. J Craniofac Surg. 2009;20(4):1186-9.

47. Baldino ME, Koth VS, Silva DN, Figueiredo MA, Salum FG, Cherubini K. Gardner syndrome with maxillofacial manifestation: A case report. Spec Care Dentist. 2019;39(1):65-71. 